\title{
MAPAS HISTÓRICOS Y GESTIÓN DE LOS RECURSOS AMBIENTALES. LA FILTRACIÓN CARTOGRÁFICA DE ÁREA Y EL CASO DE RIOMAGGIORE (CINQUE TERRE, ITALIA)
}

\author{
Anna Maria Stagno \\ Laboratorio di Archeologia e Storia Ambientale - Dafist - Università di Genova
}

\section{RESUMEN}

Este trabajo pretende mostrar un determinado método de análisis de mapas actuales e históricos denominado «filtración cartográfica de zona», mostrando su uso potencial para estudios sobre los cambios de uso del suelo y cobertura vegetal.

Este método fue desarrollado por el Laboratorio de Arqueología e Historia del Medio Ambiente (LASA - Universidad de Génova), en el marco de investigaciones sobre las transformaciones históricas de los sistemas de gestión de recursos naturales y en la identificación de los sitios de interés histórico y del medio ambiente (con especial referencia a las praderas históricas).

El método de «filtración cartográfica» considera, en un «largo plazo» temporal, los cambios en las coberturas y usos del suelo como reflejo de los cambios ocurridos en los sistemas locales de gestión ambiental. El caso de estudio propuesto se refiere a la región de Cinque Terre (SP, Italia) y la zona es un ejemplo de aplicación de este tipo de análisis en la investigación de las áreas históricas de las praderas costeras y de la dinámica postcultivo relacionada con su abandono.

Palabras clave: cartografía histórica, cambios de usos del suelo y cobertura de la vegetación, Cinque Terre (Italia), siglos XIX y XX.

\section{ABSTRACT}

This paper aims to illustrate a particular method of analysis of current and historical maps called «cartografic filtration of area», showing its potential use for studies on changes in land use and vegetation cover.

This method was specially developed by the Laboratory of Environmental Archaeology and History (LASA - University of Genoa), in the frame of researches on the historical transformations of environmental resources management systems, and on the identification of sites of historical and environmental interest (with special reference to historical grasslands).

The»cartografic filtration» method considers, in the 'long term', changes in land cover to relate them to those happened in local systems of environmental management. 
The proposed case study regards the Cinque Terre (SP, Italy) area and is an example of application of this type of analysis in the investigation of the historical areas of coastal grasslands and of the post-cultural dynamics related to its abandonment.

Key words: historical maps, land use and vegetation cover changes, Cinque Terre (Italy), $19^{\text {th }}$ and $20^{\text {th }}$ centuries.

\section{Introducción}

Este trabajo pretende ilustrar un determinado método de análisis de los mapas históricos y actuales, llamado «filtración cartográfica de área», mostrando su uso potencial para estudios sobre los cambios de uso del suelo y cobertura vegetal.

Este método ha sido desarrollado particularmente por el Laboratorio de Arqueología e Historia Ambiental (LASA - Universidad de Génova), en el curso de las investigaciones sobre las transformaciones históricas de la gestión de los recursos ambientales y la identificación de sitios de interés histórico y medioambiental (con especial referencia a las praderías históricas) ${ }^{1}$.

Las investigaciones del LASA se dirigen a la reconstrucción histórica de los sistemas y prácticas de gestión de los recursos ambientales, para caracterizar históricamente los productos locales («produits de terroir»), los paisajes y el patrimonio rural (Cevasco, 2007; Moreno y Montanari, 2008). Esta labor se lleva a cabo a través del estudio coordinado de diferentes fuentes, tanto de campo (botánicas y arqueológicas), como documentales (de archivo, mapas históricos y fotografías), tratando de alcanzar una alta resolución espacial y temporal de análisis, que permite captar y calificar las relaciones entre los diferentes fenómenos investigados ${ }^{2}$.

El método de filtración cartográfica considera, en el «largo plazo» temporal, los cambios en la cubierta vegetal para relacionarlos con los ocurridos en los sistemas locales de gestión ambiental. El estudio de caso propuesto es un ejemplo de aplicación de este tipo de análisis en la investigación de las áreas históricas de pastizales costeros y de las dinámicas de post-cultivo relacionadas con su abandono.

Este método de estudio se compara con la investigación sobre la cobertura vegetal y el uso del suelo mediante una perspectiva histórica. En el primer epígrafe se ofrece una breve reseña de estos estudios para poner de relieve la existencia de una línea de investigación que hace hincapié en un enfoque analítico para el estudio de las dinámicas de la cubierta

\footnotetext{
$1 \quad$ El Laboratorio de Arqueología y de Historia Ambiental de la Universidad de Génova, se divide en dos secciones: geográfico-histórica (DISMEC) y botánica (DIPTERIS). Para la historia y los temas de investigación del Laboratorio, consulte www.lasa.unige.it. El estudio de caso aquí presentado se inserta en el proyecto Identificación de lugares de interés histórico arqueológico y ambiental en el Patrimonio de la Humanidad «Cinque Terre, Portovenere y las islas» con los métodos de la ecología historica y de la arqueología rural (AA.VV., 2009), financiado por la Direzione Regionale per i Beni Archeologici e Paesaggistici della Liguria (Ministero per i Beni e le Attività Culturali). La investigación fue desarrollada con el proyecto Les paysages de l'arbre hors forêt: multi-valorisation dans le cadre d'un développement local durable en Europe du Sud - PAHF (AA.VV. 2010). Este proyecto fue realizado en colaboración con el Laboratorio GEODE (UMR 5602, CNRS) de la Universidad de Toulouse II (Francia) y con el Instituto de Desarrollo Regional de la Universidad de Granada, con la financiación del Ministère de l'Écologie, du développement et de l'aménagement durables (Francia).

2 Este enfoque de investigación se remite a las experiencias de la ecología histórica y de la historia local de los británicos en acuerdo con las elaboraciones metodológicas de la micro-historia (Moreno, 1990; Maggi et
} al., 2002). 
vegetal, con el fin de evitar un exceso de simplificación en la explicación de los fenómenos (Lambin, et al., 2003).

\section{Estudios sobre las transformaciones de la cubierta vegetal y del uso del suelo y análisis de la cartografía histórica}

Desde los años setenta, con el avance de la tecnología satelital para el estudio de los recursos de la tierra y la producción de mapas de uso del suelo (el primer satélite Landsat fue lanzado en 1972), el impulso hacia el desarrollo de enfoques para el estudio de los cambios en la cubierta vegetal y uso del suelo fue particularmente intenso (Goward y William, 1997; Zeng et al., 1999).

La disponibilidad de imágenes de satélite ha contribuido a la multiplicación de las técnicas de teledetección (Colwell, 1983; Richards y Jia, 2006). Este desarrollo también está relacionado con el hecho de que la teledetección permite el uso de métodos automáticos o semiautomáticos para el reconocimiento de los diferentes tipos de cubierta vegetal, una vez realizados los necesarios controles a nivel de suelo (Fuller, et al., 1994; Pu y Gong, 1998; véase también Loveland et al., 1999 para un panorama de los principales métodos de análisis). La difusión de los estudios ha llevado a abordar el problema de la codificación de criterios de clasificación y de leyendas normalizados para la comparación de investigaciones realizadas en diferentes áreas (Cingolani et al., 2004; Lambin et al., 2006, Anderson et al., 2001) .

La difusión mundial de los estudios sobre la transformación de la cubierta vegetal conecta también con la creciente necesidad de vigilar y predecir los cambios ambientales, en particular del clima. Es suficiente analizar los índices de algunas revistas internacionales dedicadas a la teledetección (por ejemplo, Remote Sensing of Environment, ISPRS Journal of Photogrammetry and Remote Sensing, International Journal of Remote Sensing) o buscar en Internet los términos «land cover» y «land use» para percatarse de la inmensa cantidad de estudios sobre estos temas - a nivel regional, nacional o global - en todas las partes del planeta.

La teledetección de imágenes de satélite se encuentra más comúnmente utilizada en el estudio de los cambios ambientales a varios niveles. Los trabajos son a menudo también sobre temas específicos como las transformaciones agrarias (por ejemplo Nagendra, et al., 2004; Thongmanivong et al., 2009), o la expansión urbana (Clarke, et al., 1997; Wilson et al., 2003; Shaban y Dikshit, 2001). De particular importancia son las investigaciones para reconocer los efectos de los cambios en el uso/cobertura del suelo sobre la biodiversidad (Woods y Skole, 1998; Zhang et al., 2007; Gurrutxaga y Lozano, 2007), también en referencia a las situaciones particulares, como las variaciones de las masas forestales y las dinámicas de la deforestación (por ejemplo, Lambin et al., 2003), desertificación (Recatalá Boix et al., 2009) o la transformación de la vegetación de los humedales (Peña et al., 2008).

Las fotografías aéreas — gracias a la mayor resolución espacial y al arco temporal más amplio - se utilizan más para la detección de fenómenos localizados, como los efectos de la

3 Un fuerte impulso para la identificación de una leyenda común ha derivado de proyectos internacionales, como el proyecto europeo Corine - Land Cover (http://www.eea.europa.eu/publications/COR0-landcover) y la codificación del sistema del Land Cover Classification System promovida por la FAO (http://www.fao.org/ docrep/003/X0596E/X0596e00.HTM). 
explotación de las minas de carbón (Mulkova y Popelková, 2010), las variaciones en tipos específicos de cultivos como el alcornoque en Cerdeña (Sedda et al., 2011) o los árboles fuera del bosque conectados con sistemas históricos de pastoreo en el sur de Francia o en Andalucía (Paegelow y Camacho Olmedo, 2003).

En general, la investigación sobre estos temas ha permitido perfeccionar las interpretaciones que vinculaban los cambios en la cobertura vegetal y uso del suelo a unos pocos factores, y ha mostrado cómo está relacionada con las interacciones específicas entre un gran número de factores a diferentes escalas espaciales y temporales (Lambin et al., 2003). Por esta razón, cada vez más, se hace hincapié en la necesidad de realizar estudios con alta resolución espacial y cubriendo un período de tiempo que supere los límites de las fuentes comúnmente utilizadas en la teledetección (Lambin et al., 2006). Las imágenes de satélite están disponibles sólo a partir de los años setenta (y las primeras con una resolución espacial baja) y las fotografías aéreas a partir de los años treinta (rara vez al principio del siglo XX). El limitado arco cronológico de observación es particularmente problemático en Europa occidental y en América del Norte, donde el abandono de las actividades agrícolas se produjo de una manera considerable, al menos desde el comienzo del siglo XX (Ramankutty et al., 2002).

Muchos de los estudios que analizan los cambios en la cobertura vegetal y uso del suelo, en una perspectiva histórica a largo plazo, utilizan fuentes estadísticas y, por tanto, discuten, aunque por encima, resultados cuantitativos. Por ejemplo, proporcionan informaciones sobre los cambios en las extensiones de los espacios dedicados a uno u otro cultivo (Goldewijk y Ramankutty, 2004: con una interesante discusión de los métodos utilizados en las investigaciones a largo plazo y de los métodos para hacerlos comparables).

Son más raras las investigaciones que también pueden ofrecer resultados cualitativos sobre los cambios en la cobertura vegetal. Se trata de estudios que no sólo discuten las variaciones en términos de extensiones, sino que también elaboran cartografía, lo que hace posible la visualización de los elementos de continuidad y de discontinuidad (Petit y Lambin, 2002). Este tipo de análisis es posible mediante la comparación de una serie de mapas topográficos, producidos en aproximadamente los últimos 200 años, desde la difusión de la cartografía de los geómetras y geodestas. Estas fuentes, sin embargo, no siempre están disponibles para una determinada área, o no lo están en forma tal como para permitir la construcción de una serie documental, lo que puede explicar el número relativamente bajo de las investigaciones que las utilizan.

El análisis efectuado en los mapas históricos por el LASA, con el objetivo de una comparación diacrónica (cualitativa y cuantitativa) de la dinámica de la cubierta vegetal, se ajusta a esta línea de investigación. En particular, el método de la filtración cartográfica tiene una cierta afinidad con el «análisis comparativo de las clasificaciones elaboradas de manera independiente», utilizada en la teledetección ${ }^{4}$. Aun en la filtración cartográfica - que es la comparación de series de documentos cartográficos producidos en la misma zona en diferentes momentos - cada mapa se asigna y se analiza de forma independiente de acuerdo con un marco de referencia común. Hay, sin embargo, una diferencia derivada del tipo de documento, que no son ni fotografías ni mapas de uso y cobertura del suelo,

$4 \quad$ El procedimiento se utiliza con éxito para una serie de investigaciones sobre la transformación de la cobertura del suelo, incluyendo las dinámicas de la deforestación, de la urbanización, los cambios en las dunas de arena y la transformaciones agrarias (Loveland et al., 1999). 
sino mapas topográficos, desarrollados de acuerdo a criterios y objetivos específicos, en ocasiones con amplias diferencias temporales ${ }^{5}$. Para hacer uso de los documentos cartográficos en el análisis de los cambios de la cobertura vegetal, es necesario «descifrar» los códigos gráficos y los sistemas de comunicación utilizados por los cartógrafos ${ }^{6}$. Como se verá en la discusión del caso de estudio, no siempre un símbolo dado puede ser interpretado sin ambigüedades, ya que la representación gráfica depende del tipo de significado que el cartógrafo quería comunicar.

\section{El estudio de las mapas históricos para la identificación de los recursos de pastizales en las investigaciones del $L A S A$}

LASA ha profundizado el estudio de mapas históricos para identificar los recursos de pastos y forrajes en relación con la reconstrucción temporal de los sistemas agropecuarios locales. Las investigaciones se centraron particularmente en la producción de los Oficiales Topógrafos del Reino de Cerdeña que, en el siglo XIX, trazaron el territorio del Reino y, dentro de este, de Liguria ${ }^{7}$. En los Apeninos de Liguria se reconstruyeron particulares sistemas de pastizales, como los pastizales arbolados (para una síntesis de estas investigaciones colectivas véase Cevasco, 2007) ${ }^{8}$. Todos estos sistemas estaban incluidos dentro de un sistema de uso múltiple de los recursos naturales, en el que el pastoreo de ganado vacuno y ovino tuvo un papel clave. Por lo menos hasta mediados del siglo XIX, todas las áreas de los Apeninos y costa de Liguria formaron parte de diferentes rutas de trashumancia estacional, que unían las zonas de pastoreo en los Apeninos, en verano, con las costeras, de invierno (Fig. 1) $)^{9}$. Estos sistemas fueron abandonados en toda Liguria en los inicios del siglo XX. Con esta cesión hubo una transformación en los sistemas de gestión de los recursos agro-forestales y de pastoreo, pasando de sistemas múltiples hacia sistemas de monocultivo que preveían, de manera permanente y exclusiva, espacios compartidos para el cultivo, los prados, los pastos y el bosque (Moreno, 1990). El progresivo abandono de las prácticas pastoriles de uso múltiple de los recursos ambientales se puede conectar con la acción comenzada desde los primeros decenios del siglo XIX para los Savoia (Reino de

5 Sobre la cuestión de la utilización de mapas históricos para el análisis de los cambios en la cobertura vegetal véase también Petit y Lambin (2002), que insisten en la cuestión de una «homogeneización» de la codificación de los datos y leyendas que permita «maximizar» la capacidad informativa de cada mapa.

6 Por esta razón, en el análisis de las fuentes cartográficas históricas no es posible el uso de métodos de reconocimiento automático de los diferentes tipos de cobertura vegetal. El LASA ha hecho propuestas específicas para un «desciframiento realista» de las fuentes cartográficas históricas, combinando su análisis con la verificación de campo utilizando los métodos de la ecología histórica (Moreno, 1995; Cevasco, 2007: 74-85).

7 Estos son los mapas de campo, dirigidos por los oficiales topógrafos del Cuerpo de Estado Mayor del Reino de Cerdeña, a escala 1: 9.450, entre 1816 y 1825, y a escala 1: 20.000 en torno a 1828. Estos mapas fueron preparatorios de la Gran Carta de los Estados Continentales de Cerdeña (Gran Carta degli Stati Sardi di Terraferma) a escala 1: 50.000, actualizada, con estudios y reconocimientos de campo, entre 1830 y 1840 , a escala 1: 20.000, y publicada desde 1852 hasta 1870. Para una discusión sobre esta producción véase Moreno (1995) y, específicamente para la Gran Carta Marullo (2002).

8 El trabajo «pionero» en este tipo de investigación fue el de Moreno y Poggi (1996). El estudio de pastizales arbolados fue profundizado particularmente en el proyecto PAHF, que ha prestado especial atención al papel de los «árboles fuera del bosque» en los sistemas históricos de utilización de los recursos naturales que combinaban las necesidades de los pastos con la agricultura y la silvicultura (AA. VV., 2010).

9 En muchas áreas de la Liguria estos sistemas de conexión entre la costa y las montañas se han documentado con continuidad - a través el estudio de fuentes documentales y cartográficas históricas - al menos desde el siglo XVII hasta finales del siglo XIX (Moreno, 1990; Moreno y Raggio, 1990). 


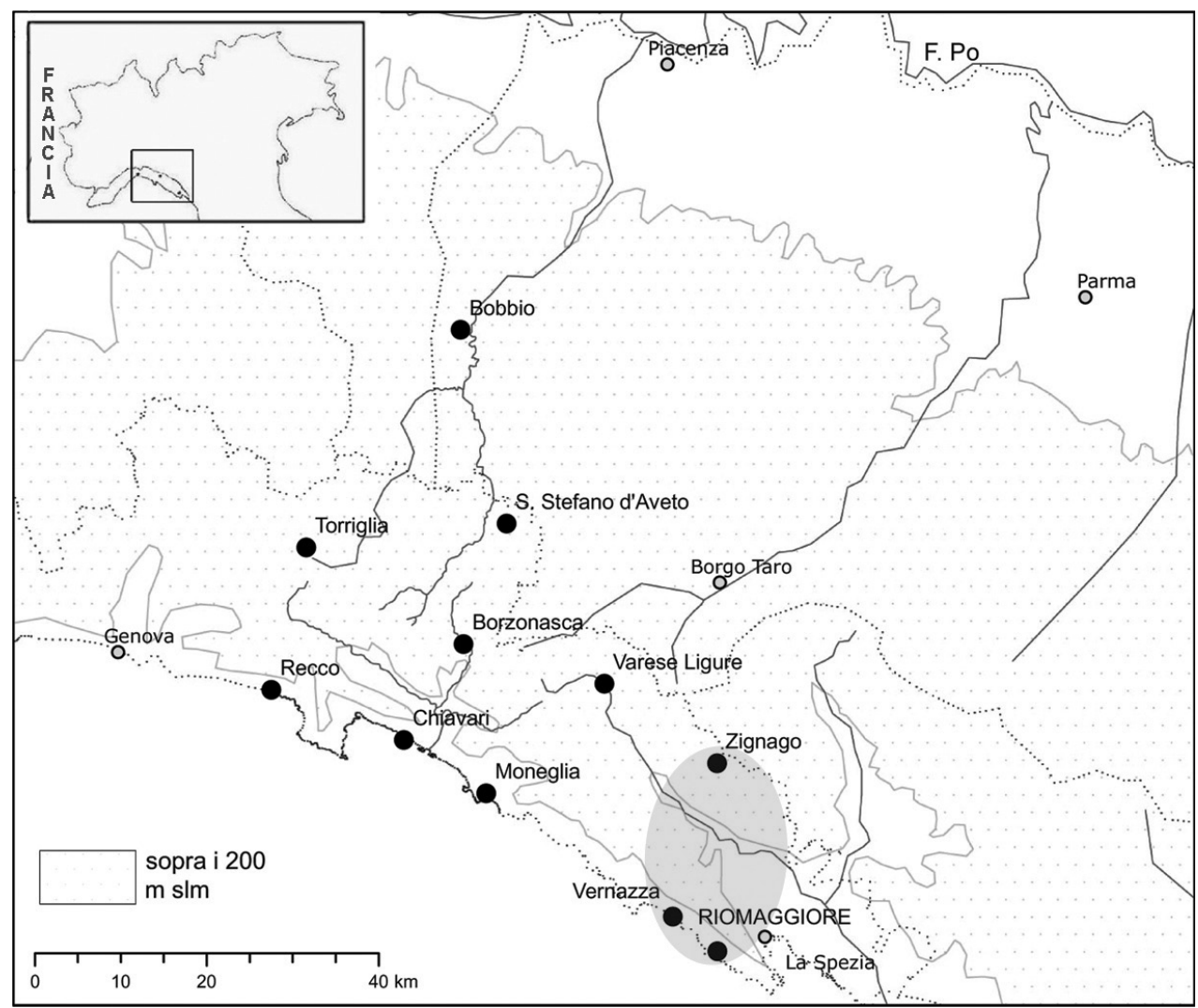

FIgURA 1. Localización de la área de investigación (2003-2010) en el contexto de los estudios del LASA sobre los sistemas de trashumancia en el Apenino Ligur oriental.

Cerdeña), con el fin de normalizar, en la dirección del monocultivo, la gestión de los recursos forestales, con la cesión de los sistemas de trashumancia (Moreno, 1990: 54-56, 222; Moreno y Raggio, 1990) y del papel comercial de los pasos de los Apeninos (Stagno, 2009).

El estudio de la cartografía histórica en tres áreas diferentes de Liguria (Val Petronio, Val d'Aveto, Riomaggiore) ha permitido individualizar las trazas cartográficas del comienzo de esta transformación ${ }^{10}$. Por ejemplo, es posible observar un importante cambio entre las representaciones cartográficas de 1818 (Tablillas de campo) y la de 1854 (Gran Carta de los Estados Continentales de Cerdeña). Mientras que, en los mapas de 1818, numerosas áreas estaban representadas como áreas con árboles aislados, en 1854 estos se representan como zonas boscosas; además, mientras que en 1818 no era posible distinguir entre los espacios utilizados como prados o como pastos, en los mapas de 1854, estos se distinguen con el uso de símbolos diferentes («Gerbidi»y «Pascoli»).

10 Para la Val d'Aveto véase Stagno (2009); Moreno et al. (2010); para la Val Petronio, Cevasco et al. (2005) 
El caso que voy a discutir es particularmente ilustrativo de este fenómeno y se centra en los cambios de un área conocida mundialmente por sus hermosas laderas en terrazas y su especialización en la producción de vino: las Cinque Terre.

\section{Estudio de caso: los recursos de pastizales en el municipio de Riomaggiore (Cinque Terre)}

\subsection{Estado de la cuestión. Los recursos de los pastos y los viñedos en terrazas}

El estudio desarrolla las investigaciones previas de ecología histórica, dirigidas por LASA, que tenían como objetivo aclarar el papel de la trashumancia en la economía rural de las Cinque Terre y la dinámica post-cultivo de la cubertura vegetal ${ }^{11}$.

Las investigaciones han permitido reconocer las huellas históricas de un paisaje rural más complejo que el actual - dominado por la vid y el olivo- en el que junto a las terrazas (de castaños, vides y olivos) habían espacios costeros dedicados al pastoreo (Maggi et al., 2006). Estos espacios formaban parte de un circuito donde, estacionalmente, miles de animales se movían a lo largo de las cordilleras del interior (las zonas de agostadero en el área de Zignago), hasta los pastos de la costa, donde permanecían durante los meses de invierno (Fig. 1) (2) $^{12}$.

La investigación ha demostrado que el sistema de gestión que giraba en torno a la trashumancia era una estructura funcional que se basaba en el uso de las tierras colectivas (comunaglie) y de los recursos pastorales en las tierras de propiedad privada (viñedos, olivos, castaños) ${ }^{13}$. Hasta mediados del siglo XIX, de hecho, los viñedos se abrían al pastoreo en los meses de otoño e invierno (tanto para el ganado local, como por la trashumancia de ovejas), lo que ha permitido, durante siglos, la reintegración de la fertilidad de las terrazas ${ }^{14}$. Este sistema tiene una comparación con otras áreas geográficas de viticultura intensiva, como las de Burdeos, donde hasta el final del siglo XIX, después de la cosecha, los rebaños que bajaban de los Pirineos podían acudir a las Landas (Rendu, 2003).

11 Las investigaciones históricas se llevaron a cabo en un proyecto promovido por la Superintendencia de Patrimonio Arquitectónico y Paisaje de la Liguria. El proyecto Sitios Lemmen y Cacinagora (Riomaggiore - SP). Estudios e investigaciones para identificar los efectos de las prácticas agro-silvo-pastorales y las dinámicas de post-cultivo de la cubierta vegetal, fue promovido para la recuperación medioambiental del Parque Nacional de las Cinque Terre (AA.VV., 2003). Los estudios se continuaron luego en el proyecto que originó el caso discutido aquí (véase nota 1).

12 En 1820 la trashumancia invernal supuso un flujo de 4.000 ovejas en las alturas de Riomaggiore (Gasparini, 2001). En la primera mitad del siglo XIX, los documentos de archivo muestran cómo, en los pueblos de las Cinque Terre, el estiércol fue moneda de cambio importante. En Riomaggiore, de hecho, la venta de «Noches de lettame» (estiércol) era una práctica vigente (ibidem): se trataba de uno de los bienes más valiosos para una agricultura especializada como la de Riomaggiore, que recuerda las prácticas de las comunidades pastoriles de los Alpes de Liguria, reguladas por estatutos medievales (AA.VV., 2003: 85-86).

13 En muchas zonas de Liguria sobreviven, aun hoy, derechos colectivos sobre las tierras que ahora son bienes fraccionales (beni frazionali) y que en el pasado, a lo largo de Liguria, cayeron en la definición de «comunaglie» (por el estudio de las «comunaglie» en Liguria, ver Reggio (1992); Stagno y Tigrino (2011); en general sobre el problema de las tierras comunales véase Agrawal (2003) y Rodgers et al. (2010). Entre los siglos XVII y XVIII, hay muchos conflictos sobre los derechos de uso y posesión de las «comunaglie», que en muchos casos terminan con la venta (Raggio, 1992). Conflictos similares están documentados en el área de Riomaggiore, en el siglo XIX, en relación con la expansión de las terrazas de viña (AA.VV., 2003: 85).

14 Esta reconstrucción fue posible a través del estudio de las fuentes fiscales disponibles para la área entre los siglos XVII y XIX (AA.VV., 2003). 
Desde finales del siglo XVIII, las Cinque Terre se especializaron, de forma progresiva, en la producción del vino ${ }^{15}$. En las últimas décadas del siglo XIX, cuando el sistema de las ovejas trashumantes finalizó (y, con él, también la restauración de la fertilidad a través del pastoreo), la viticultura en el Cinque Terre sufrió una carencia de abonos y fertilizantes, como demuestran documentos técnicos de finales de siglo (Montanari et al., 2010). Desde la Segunda Guerra Mundial la especialización de la producción del vino emprendió un declive irreversible, relacionado con el cambio en la demanda del mercado (y con los métodos de producción de las otras áreas), con el resultado de un abandono generalizado de los cultivos (Storti, 2007).

Los trabajos del LASA analizaron, de acuerdo con los métodos de investigación de la ecología histórica, los efectos de las rutas de la trashumancia en la vegetación y en el suelo en el sector situado entre el eje de los Apeninos y la costa de este área, partiendo de los supuestos de que existía un sistema de corredores herbáceos de conexión entre la zona de las «colinas» y la del «mar»; que dicha conexión de diferentes hábitats había contribuido a la mezcla y la interacción entre especies con diferentes requerimientos ecológicos; y que, después del abandono definitivo de los sistemas históricos de la trashumancia, los rastros de estas rutas podían ser aún reconocibles en la flora y la vegetación de las Cinque Terre, gracias a la presencia de especies indicadoras de pastoreo (AA.VV., 2003, Guido et al., 1996). La investigación también permitió reconocer la presencia de núcleos de bosque y de pastizales supuestamente antiguos, ya que están documentados de forma continuada desde 1820 .

La nueva filtración cartográfica del área del municipio de Riomaggiore tenía por objeto verificar estas hipótesis documentando el alcance y las características de las estaciones de pasto, de los corredores herbáceos y de los núcleos de bosques antiguos (presentes en 1820). También pretendía evaluar la entidad de las dinámicas post-cultivo que se han dado en la cubierta vegetal tras el abandono de la agricultura y de las actividades pastoriles.

\subsection{Las fuentes utilizadas en la filtración: evaluación y restitución informática}

Las fuentes investigadas son un conjunto de mapas que abarcan el período comprendido entre 1820 y 1999. Estos son:

- Mapas, copias en limpio (1827-1832) de las cartillas de campo, dirigidas por los oficiales topógrafos del Cuerpo de Estado Mayor del Reino de Cerdeña, entre los años 1816-1827, a escala 1:9.450 ${ }^{16}$. En este texto nos referiremos a ellas como Mapas manuscritos de 1820.

- Gran Carta de los Estados Continentales de Cerdeña (Gran Carta degli Stati Sardi di Terraferma), copia litografiada, 1853, a escala 1: 50.000, F. LXXXIV Spezia. En este texto la denominaremos Gran Carta de 1853.

- Mapas del Instituto Geográfico Militar (Istituto Geografico Militare), Firenze - F. 95 II N.O. Spezia, a escala 1: 25.000, serie histórica, diseño de 1877, reconocida sobre el terreno en 1904. En el texto se denomina IGM 1904.

15 En Riomaggiore, en 1643, aproximadamente el 50\% de las tierras estaba cultivado con vides, mientras que en 1799, se elevó a 63,3\% y hasta el 75,45\%, entre el 1918-1932, cuando se puso en cultivo las tierras primeramente ocupadas por el castaño. La máxima expansión de los viñedos en terrazas se llevó a cabo entre 1850 y 1930 aproximadamente (Storti, 2007).

16 Estos mapas se conservan en el Archivio Cartografico de el Istituto Geografico Militare, Sede San Marco, IGM, Firenze, Doc. 252 Cart. 32 (ff. 7, 8, 15). Sobre algunas noticias de estos documentos y sobre los autores véase http://www.igmi.org/ancient/scheda.php?cod=16722. 
- Mapas del Instituto Geográfico Militar (Istituto Geografico Militare), Firenze - F. 95 II N.O. La Spezia, relieve aéreo-fotogramétrico de 1938, a escala 1:25.000. En el texto se denomina IGM 1938.

- Mapa Técnico Regional - Región de Liguria, relieve aéreo-fotogramétrico de 1988, a escala 1: 25.000, secciones 248.3 Fabiano, 248.4 La Spezia. De ahora en adelante, la denominaremos CTR 1988.

- Mapa Técnico Regional - Región de Liguria, relieve aéreo-fotogramétrico de 1999, versión raster a escala 1:10.000, secciones 248100 Fabiano, 248050 Riomaggiore - Vernazza, 248060 La Spezia. En el texto se denomina CTR 1999.

Los documentos cartográficos analizados muestran diferencias significativas en la restitución de la cubierta vegetal y del uso del suelo. El distinto grado de capacidad informativa está relacionado, en particular, con los diferentes fines de la redacción y con el uso de diversas representaciones simbólicas. Por lo tanto, ha sido necesario analizar los símbolos en cada mapa y sucesivamente interpretarlos para hacerlos comparables. Durante este trabajo, algunos problemas de lectura se han resuelto mediante la comparación entre los diferentes mapas analizados.

La filtración cartográfica se llevó a cabo en un entorno SIG. Los mapas fueron georreferenciados sobre la base de la CTR 1999 (escala 1:10.000). Sólo para la Gran Carta de 1853 fue necesario rectificar el mapa, mientras que en otros casos la superposición simple se consideró suficientemente precisa, por lo que no requirió una mayor elaboración. En la discusión de la filtración y en el procesamiento de los mapas se han tomado, como referencia, la forma de los nombres de lugares y las alturas, como aparecen en el CTR 1999 (escala 1:10.000), que corresponde a la escala en que la filtración se ha llevado a cabo.

Tras ello realizamos una breve discusión sobre el tratamiento y el retorno de cada mapa analizado.

\section{Mapas manuscritos de 1820}

Los Mapas manuscritos de 1820 están realizadas con acuarela: representan la topografía con sombreado y la luz oblicua, los asentamientos en rojo, las aguas en azul, la vegetación y los cultivos en verde, las carreteras en negro (Fig. 2). Aportan numerosos micro-topónimos y representan la línea rocosa de costa con un rasgo irregular y sombreado ${ }^{17}$.

En la cubierta vegetal se reconocen:

- áreas abiertas, representadas con el color de fondo, sin otras caracterizaciones.

- núcleos de bosque más o menos densos, representados en verde oscuro.

- Terrazas, simbolizadas con líneas verde claro paralelas en el perfil de la ladera y, en algunos casos, con la caracterización de la cubierta vegetal.

Estas tres diferenciaciones corresponden a tres categorías que han sido mantenidas en el análisis de todos mapas y en la elaboración informática, para uniformar la elaboración de cada mapa en la filtración cartográfica (Tab. 1). De hecho, la simple leyenda construida con estas categorías permite reconocer rápidamente las diferencias en la cubierta vegetal y puede ser común a todos los mapas analizados en la serie cartográfica.

17 Elementos adicionales para la interpretación se pueden extraer de la comparación con los mapas de campo de 1828, dibujados a escala 1:20.000, que tienen siglas relacionadas con el uso del territorio (AA. VV., 2003: 56-67). 


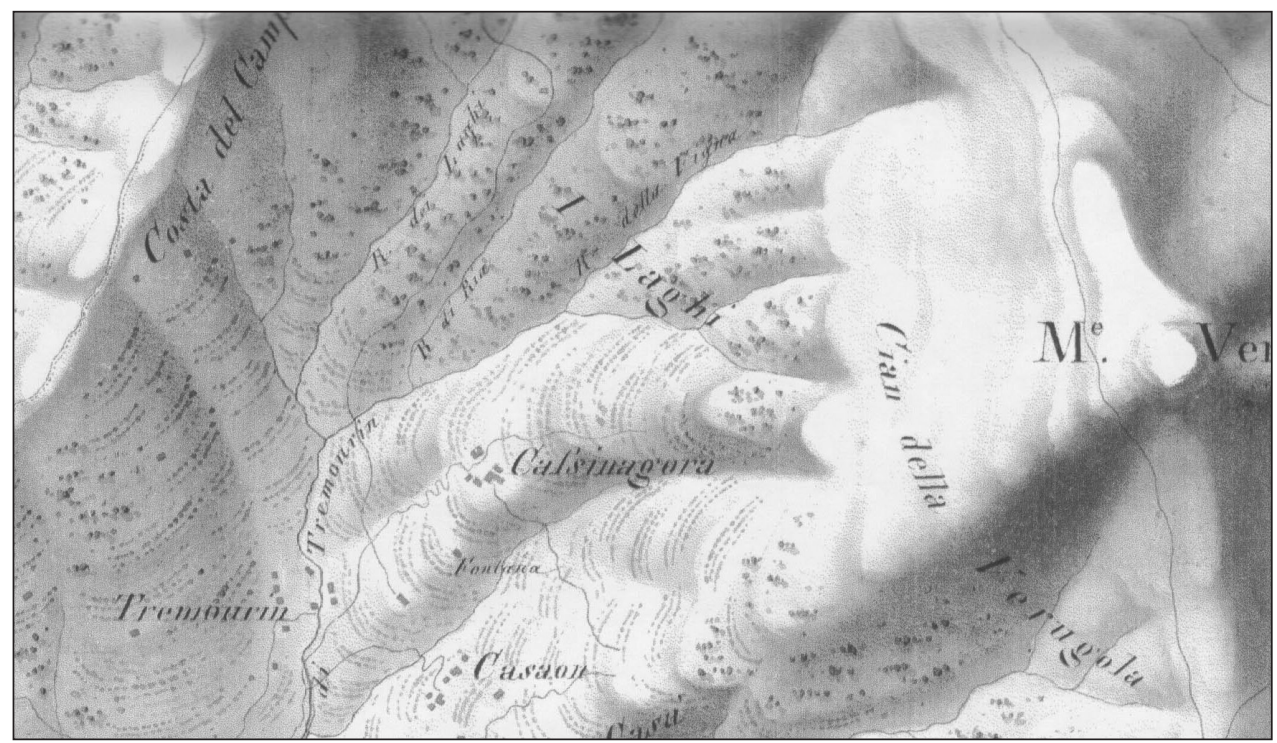

Figura 2. Detalle del Mapa manuscrito de 1820 del área del sitio de Cassinagora (Cacinagora), donde se observa la caracterización de las áreas abiertas, boscosas y de terrazas.

Tabla 1

NORMALIZACIÓN DE LOS SÍMBOLOS DE LAS TABLAS MANUSCRITAS DE ACUERDO CON LAS CATEGORÍAS ADOPTADAS EN LA FILTRACIÓN CARTOGRÁFICA

\begin{tabular}{|l|l|}
\hline \multicolumn{1}{|c|}{ Descripción de los símbolos de las Tablas manuscritas $\mathbf{1 8 2 0}$ analizadas } & leyenda adoptada \\
\hline $\begin{array}{l}\text { Áreas abiertas, representadas con el color de fondo, sin otras } \\
\text { caracterizaciones }\end{array}$ & áreas abiertas \\
\hline $\begin{array}{l}\text { Núcleos de bosque más o menos denso, caracterizados con el fondo } \\
\text { en verde oscuro }\end{array}$ & áreas boscosas \\
\hline $\begin{array}{l}\text { Terrazas, simbolizadas con líneas verde claro paralelas al perfil de la } \\
\text { ladera }\end{array}$ & áreas de terrazas \\
\hline $\begin{array}{l}\text { Asentamientos en rojo (en el análisis, los edificios individuales o } \\
\text { pequeños grupos de casas no fueron considerados) }\end{array}$ & áreas edificadas \\
\hline línea rocosa de costa representada con un rasgo irregular y sombreado & costa \\
\hline
\end{tabular}

\section{Gran Carta de 1853}

La Gran Carta de 1853 es una reproducción litográfica en negro y azul del documento original, tirado a pluma en varios colores. Se representan asentamientos (edificios y grupos de edificios se representan con fondo negro), caminos (líneas finas en negro), cursos de agua (líneas finas en azul) y la línea de costa rocosa (con un trazo irregular). El tipo de 

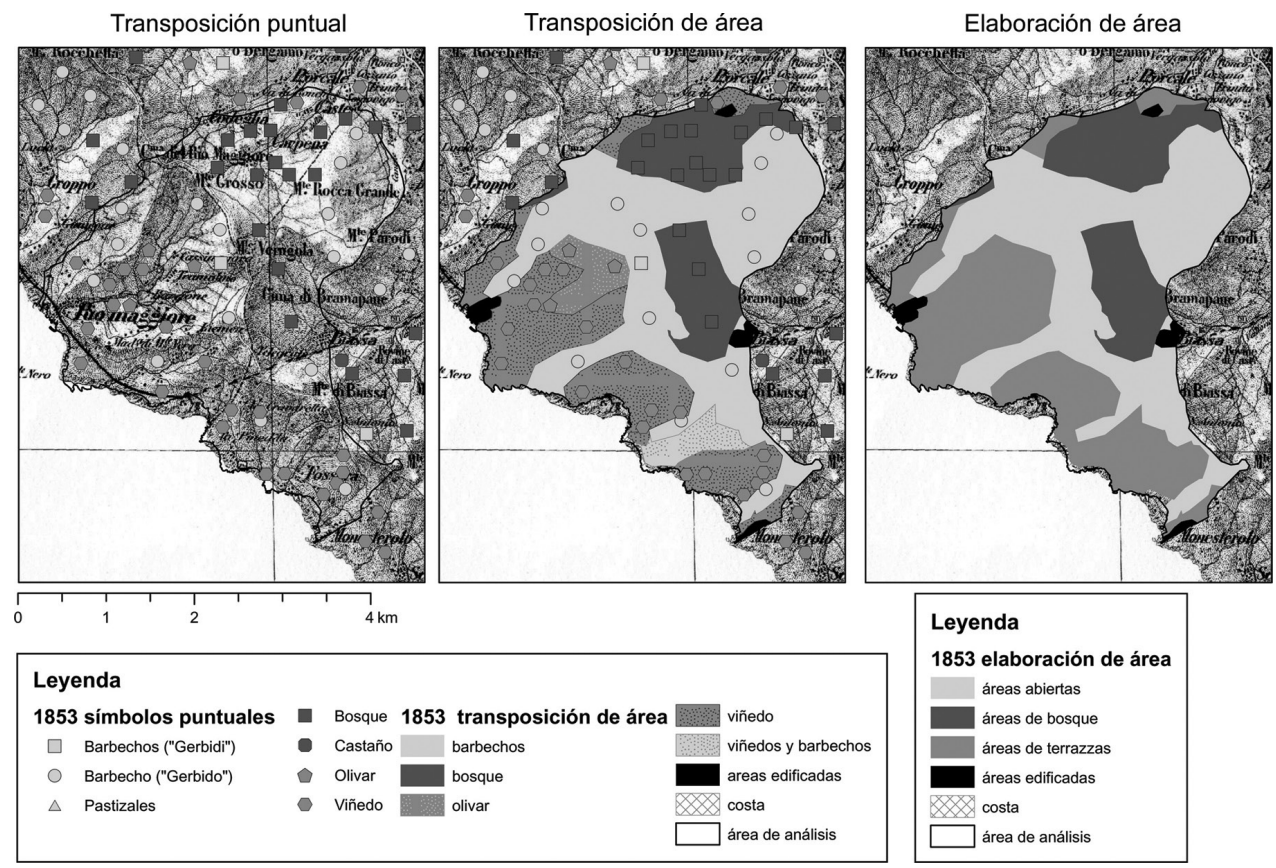

FIGURA 3. Riomaggiore, área de análisis. Fases de la interpretación de la Gran Carta de 1853 realizadas mediante la filtración cartográfica. Reducción del original a la escala 1:50.000.

Tabla 2

«CUALIDAD DE LOS CULTIVOS»REPRESENTADOS EN LA PORCIÓN DE GRAN CARTA DE 1853 ANALIZADA Y SU NORMALIZACIÓN DE ACUERDO CON LA LEYENDA DE LA FILTRACIÓN CARTOGRÁFICA

\begin{tabular}{|l|c|}
\hline \multicolumn{1}{|c|}{ «cualidad de los cultivos» } & normalización en la leyenda adoptada \\
\cline { 1 - 1 } $\mathrm{Go}, \mathrm{G}, \mathrm{Gi} \mathrm{i}^{\circ}=$ barbechos $($ «gerbidi») & áreas abiertas \\
\cline { 1 - 1 } $\mathrm{P}, \mathrm{P}^{\mathrm{i}}=$ pastizal & áreas boscosas \\
\hline $\mathrm{B}=$ bosque & áreas de terrazas \\
\cline { 1 - 2 } $\mathrm{V}=$ viñedo & \\
\hline $\mathrm{O}=$ olivar & \\
\hline
\end{tabular}

cultivos («cualidad de los cultivos») se representa con siglas puntuales de acuerdo con una leyenda estándar (ver Tabla 2).

Las siglas puntuales hacen difícil individualizar el alcance de cada cultivo representado. Para construir la interpretación de la Gran Carta, se procedió por etapas (Fig. 3):

- cartografía de cada símbolo con puntos (transposición puntual),

- reconstrucción del posible perímetro de distribución de cada símbolo a través de la comparación con las Tablas manuscritas de 1820 y, cuando ha sido posible, con las 
Tablillas IGM de 1904 y de 1938 (transposición de área). A lo largo de los límites de la zona estudiada, se le otorgaron los símbolos presentes en las zonas vecinas.

- Elaboración del área normalizada de acuerdo con las categorías utilizadas en la filtración cartográfica de área (elaboración de área).

\section{IGM 1904}

La Tablilla IGM 1904 no presenta, en teoría, dificultad de interpretación, ya que la representación gráfica adoptada corresponde con la actual, con la orografía representada con las curvas de nivel y la leyenda completamente normalizada. En el momento del análisis, sin embargo, ha demostrado ser inútil ya que las áreas de terrazas no siempre se hallan representadas, incluso cuando se han documentado ya en 1853 y 1820 .

\section{IGM 1938}

La tablilla IGM 1938 se llevó a cabo mediante el relieve aéreo-fotogramétrico y la representación gráfica adoptada corresponde a la actual: las montañas están representadas mediante curvas de nivel y la leyenda está completamente normalizada ${ }^{18}$.

No presenta dificultades de interpretación para la identificación de las terrazas, de las áreas completamente abiertas y de las zonas, sin duda, boscosas (la mayor concentración de puntos significa bosque denso). Las áreas están representadas con una caracterización que no indica bosque, pero los árboles dispersos o escasos fueron normalizados dentro de las dos categorías de «áreas boscosas» o «áreas abiertas», comparando el análisis y la interpretación de la cobertura de 1938 con la de 1904, de 1854 y 1988. En algunos casos, estas zonas han sido asignadas a las «áreas abiertas», en otros a las «áreas boscosas».

\section{CTR 1988 y CTR 1999}

Estos dos mapas se discuten juntos, ya que fueron realizados con la misma finalidad (la producción de Mapas Técnicos Regionales), modalidad (por relieve aéreo-fotogramétrico) y leyenda normalizada. Estos mapas no presentan dificultades de interpretación, representan el tipo de uso y la dedicación tanto de las zonas boscosas (de castaños, de pinos, etc.), como de las terrazas (viñas, olivos, árboles frutales). En la elaboración cartográfica estos usos fueron interpretados según las categorías de la filtración. Análogamente a la tablilla IGM 1938, también en estos casos las áreas con árboles dispersos fueron interpretadas a la luz de la comparación con los otros mapas de la serie cartográfica.

Estos documentos fueron objeto de una mayor elaboración. A partir del CTR 1988, de hecho, la expansión del bosque y el abandono de las áreas de terrazas empiezan a ser evidentes, siendo patente en el CTR 1999. La terrazas abandonadas son reconocibles porque se trata de áreas representadas como terrazas en los mapas precedentes (IGM 1938 por el CTR 1988, y CTR 1988 por el CTR 1999), y después como espacios abiertos (sobre todo en el CTR 1988) o como zonas boscosas (sobre todo en el CTR 1999). Al tratarse del reconocimiento de las dinámicas de abandono del cultivo uno de los objetivos de la filtración, en la leyenda de análisis a partir de 1988 fue introducida la voz «terrazas abandonadas».

Igualmente, a través la comparación con los mapas precedentes fue posible reconocer las neoformaciones de bosque que ocuparon espacios abiertos y, como hemos dicho, terrazas.

18 En este mapa los edificios militares no están representados, de forma que algunas estructuras existentes, como el Fuerte de M. Parodi, no se representan en la restitución cartográfica. 
Tabla 3

PROCESAMIENTO DEL CTR 1988. INTERPRETACIÓN PARA LA FILTRACIÓN DE LAS CLASES DE COBERTURA VEGETAL/ USO DEL SUELO DEL MAPA

\begin{tabular}{|c|c|}
\hline Representación en el CTR 1988 & Interpretación \\
\hline áreas abiertas & \multirow{2}{*}{ áreas abiertas, terrazas abandonadas } \\
\hline árboles dispersos & \\
\hline bosque de castaños & áreas boscosas, neoformaciones de bosque \\
\hline bosque de castaños y pinos & \multirow{2}{*}{$\begin{array}{l}\text { áreas boscosas, neoformaciones de bosque, terrazas aban- } \\
\text { donadas }\end{array}$} \\
\hline bosque de pinos & \\
\hline terrazas & \multirow{4}{*}{ áreas de terrazas } \\
\hline terrazas de olivos & \\
\hline terrazas de viña & \\
\hline árboles frutales & \\
\hline
\end{tabular}

Para restituir todas las dinámicas post-cultivo conectadas con el abandono, fue realizada una ulterior elaboración, en que están representadas tanto las terrazas abandonadas, como las neoformaciones de bosque que si ocuparon espacios abiertos (Fig. 4).
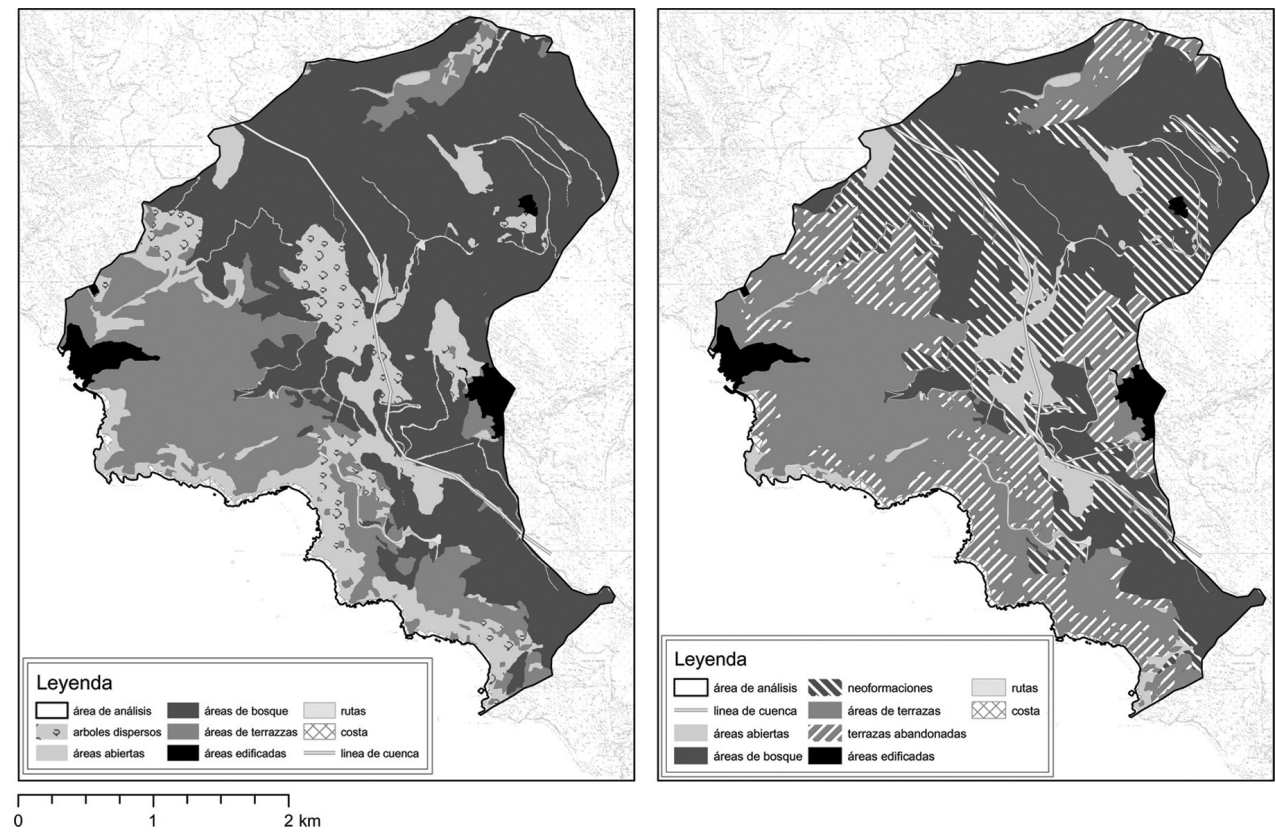

FIGURA 4. Riomaggiore, área de análisis. Fases del análisis del CTR 1999. A la izquierda, elaboración cartográfica antes de la filtración (a la derecha), que permitió de reconocer las terrazas abandonadas y las neoformaciones de bosque. 
En el análisis del CTR 1999, las terrazas abandonadas y las neoformaciones de bosque incluyen también las áreas que resultaban ya abandonadas en 1988. Las tablas siguientes (Tablas 3 y 4) muestran la interpretación de las diferentes clases de cobertura vegetal de los mapas CTR (Fig. 4 relativa al CTR 1999).

Tabla 4

PROCESAMIENTO DEL CTR 1999. INTERPRETACIÓN PARA LA FILTRACIÓN DE LAS CLASES DE COBERTURA VEGETAL/ USO DEL SUELO DEL MAPA

\begin{tabular}{|c|c|c|}
\hline Representación en el CTR 1999 & Primera elaboración & Segunda elaboración \\
\hline áreas abiertas & $\begin{array}{l}\text { áreas abiertas, terrazas } \\
\text { abandonadas }\end{array}$ & $\begin{array}{l}\text { áreas abiertas, terrazas } \\
\text { abandonadas }\end{array}$ \\
\hline $\begin{array}{l}\text { monte bajo de robles y } \\
\text { castaños }\end{array}$ & $\begin{array}{l}\text { zonas boscosas, terrazas } \\
\text { abandonadas }\end{array}$ & $\begin{array}{l}\text { zonas boscosas, terrazas } \\
\text { abandonadas }\end{array}$ \\
\hline árboles dispersos & $\begin{array}{l}\text { áreas abiertas, zonas } \\
\text { boscosas, terrazas } \\
\text { abandonadas }\end{array}$ & $\begin{array}{l}\text { áreas abiertas, zonas } \\
\text { boscosas, neoformaciones } \\
\text { de bosque, terrazas } \\
\text { abandonadas }\end{array}$ \\
\hline bosque de castaños & \multirow{6}{*}{$\begin{array}{l}\text { zonas boscosas, terrazas } \\
\text { abandonadas }\end{array}$} & \multirow{6}{*}{$\begin{array}{l}\text { zonas boscosas, } \\
\text { neoformaciones de bosque, } \\
\text { terrazas abandonadas }\end{array}$} \\
\hline $\begin{array}{l}\text { monte bajo de castaños y } \\
\text { pinos }\end{array}$ & & \\
\hline monte bajo de castaños & & \\
\hline $\begin{array}{l}\text { bosque denso de castaños } \\
\text { y pinos }\end{array}$ & & \\
\hline bosque de pinos & & \\
\hline $\begin{array}{l}\text { bosque de castaños, robles } \\
\text { y pinos }\end{array}$ & & \\
\hline bosque denso de castaños & \multirow{3}{*}{ zonas boscosas } & \multirow{2}{*}{$\begin{array}{l}\text { zonas boscosas, } \\
\text { neoformaciones de bosque }\end{array}$} \\
\hline bosque de castaños y pinos & & \\
\hline bosque denso de pinos & & zonas boscosas \\
\hline olivos dispersos & terrazas abandonadas & terrazas abandonadas \\
\hline áreas de terrazas & \multirow{6}{*}{ áreas de terrazas } & \multirow{6}{*}{ áreas de terrazas } \\
\hline árboles frutales & & \\
\hline terrazas de olivos & & \\
\hline terrazas de viña & & \\
\hline trazas de terrazas & & \\
\hline olivar & & \\
\hline
\end{tabular}




\subsection{Los resultados de la filtración cartográfica}

Las transformaciones de la cubierta vegetal en Riomaggiore, entre 1820 y 1999, se observan claramente a través de la comparación de las filtraciones de área de cada mapa analizada (Fig. 5, Tablas 5 y 6).

Tabla 5

RIOMAGGIORE. DINÁMICAS DEL USO DEL SUELO/CUBIERTA VEGETAL (1820-1999). VARIACIONES DE SUPERFICIE

\begin{tabular}{|l|c|c|c|c|c|}
\hline \multicolumn{1}{|c|}{ HECTÁREAS } & $\mathbf{1 8 2 0}$ & $\mathbf{1 8 5 3}$ & $\mathbf{1 9 3 8}$ & $\mathbf{1 9 8 8}$ & $\mathbf{1 9 9 9}$ \\
\hline áreas abiertas & 527,84 & 515,39 & 293,17 & 206,59 & 74,89 \\
\hline áreas de bosque & 271,75 & 220,1 & 423,72 & 465,66 & 572,81 \\
\hline áreas de terrazas & 342,85 & 402,98 & 413,11 & 294,69 & 267,08 \\
\hline terrazas abandonadas & - & - & - & 147,68 & 190,34 \\
\hline total analizado & 1163,3 & 1163,3 & 1163,3 & 1163,3 & 1163,3 \\
\hline
\end{tabular}

Tabla 6

RIOMAGGIORE. DINÁMICAS DEL USO DEL SUELO/CUBIERTA VEGETAL (1820-1999). VARIACIONES DE SUPERFICIE EN PORCENTAJE

\begin{tabular}{|l|c|c|c|c|c|}
\hline \multicolumn{1}{|c|}{ PORCENTAJE } & $\mathbf{1 8 2 0}$ & $\mathbf{1 8 5 4}$ & $\mathbf{1 9 3 8}$ & $\mathbf{1 9 8 8}$ & $\mathbf{1 9 9 9}$ \\
\hline áreas abiertas & 45,37 & 44,3 & 25,2 & 17,76 & 6,43 \\
\hline asear de bosque & 23,36 & 18,92 & 36,43 & 40,03 & 49,2 \\
\hline áreas de terrazas & 29,47 & 34,64 & 35,52 & 25,33 & 22,94 \\
\hline terrazas abandonadas & - & - & - & 12,69 & 16,35 \\
\hline
\end{tabular}

Para clarificar los sucesivos procesos de análisis, la interpretación de los resultados se trata de forma subdividida para cada mapa. Al final del epígrafe 4 (4.4) se presenta una breve discusión general.

\section{Mapas manuscritos de 1820}

El análisis de las Mapas manuscritos de 1820 (Fig. 5a) muestra una situación donde las área abiertas prevalecen claramente (528 ha por un área total de 1163 ha, véase Tablas 5 y 6). Estas áreas abiertas eran utilizadas como pastizales y se extendían inmediatamente al norte de los viñedos en terrazas y de los castaños, más allá de la cuenca $(600 \mathrm{~m} \mathrm{snm})^{19}$. A través de corredores abiertos localizados en las crestas de las laderas con terrazas, las áreas abiertas descienden hasta $100 \mathrm{~m}$ snm (en el área analizada se reconocen cuatro de estos corredores). Estos pasillos que «serpentean» en las terrazas -y que corresponden a los corredores herbáceos anotados en las precedentes investi-

19 Estas áreas abiertas eran tierras comunes («comunaglie») de la comunidad de Riomaggiore. 

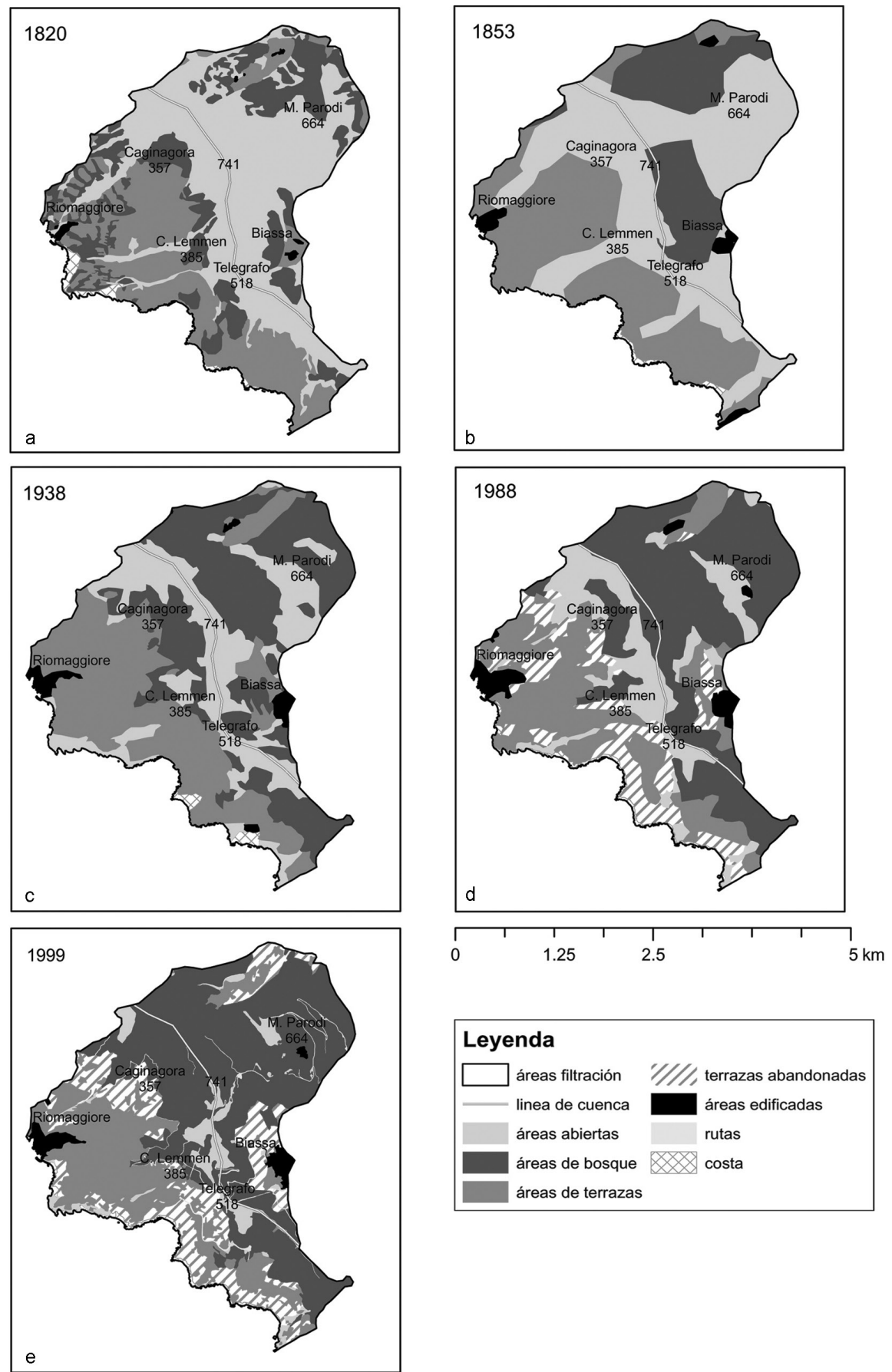

Figura 5. Riomaggiore, área de análisis. Dinámicas del uso y cobertura vegetal (1820-1999). Tabla de resumen con las filtraciones de cada mapa. 
gaciones del LASA - constituyen el indicio cartográfico de la modalidad que permitió el acceso a los recursos pastoriles (herbáceos) de los viñedos, que eran abiertos por el pastoreo en los meses de otoño y de invierno, dentro del sistema estacional de pastizales entre el interior y la costa.

Las zonas boscosas (272 ha) se concentran, sobre todo, en la parte norte del área analizada. Núcleos más pequeños de bosques están representados cerca de las terrazas, bajo de la línea de cuenca, en la zona de contacto entre las terrazas y las áreas abiertas y en el entorno de la divisoria de aguas.

\section{Gran Carta de 1853}

El análisis de la Gran Carta de 1853 (Fig. 5b), aunque con algunas incertidumbres en la interpretación debido a la transposición de símbolos puntuales hacia la representación de área, permite algunas consideraciones sobre las dinámicas de la vegetación.

Al norte de la línea de cuenca, dominan la áreas abiertas (representada con G, de «Gerbidi», barbechos), tal y como ocurre en el mapa precedente. Se observa, sin embargo, una simplificación, porque se representa una gran área de bosque y no de núcleos pequeños, como en 1820. Esta representación puede estar conectada con la escala de redacción del mapa, pero puede estarlo, también, con transformaciones en el sistema de gestión de los recursos ambientales. Los corredores que conectaban la amplia zona de áreas abiertas en la costa se reconocen únicamente por la presencia de barbechos entre los terrazos. Desaparecen los núcleos de bosque en las divisorias, lo que determina una reducción en la extensión de las áreas de bosque (véanse Tablas 5 y 6 , ¿simplificación debida a la escala o expansión de las terrazas?). Los símbolos en las terrazas muestran que los viñedos prevalecen y se extienden en toda el área al sur de la cuenca, interrumpidos solo por los corredores, y por algunos núcleos de olivares en la parte central del área analizada.

\section{Mapa IGM 1938}

El análisis del mapa IGM 1938 (Fig. 5c) muestra la reducción de las áreas abiertas (293 ha). Al norte de la línea de cuenca, las áreas abiertas documentadas anteriormente son substituidas por áreas de bosque (423 ha en total). Las áreas abiertas se reconocen solo en torno a Mte. Parodi y a la línea de cuenca, pero resultan más estrechas que antes. Los corredores abiertos que bajaban al mar se reconocen, únicamente por la presencia de algunas manchas constituidas por pequeñas islas de áreas abiertas cerca de la costa. Las áreas abiertas, al sur de la línea de cuenca, son substituidas por las terrazas que ocupan todas las laderas entre los $400 \mathrm{~m}$ snm. Esta expansión corresponde a la intensificación del cultivo de la viña documentada entre la mitad del Ochocientos y el inicio del siglo XX, descrita anteriormente.

La desaparición de las áreas abiertas al norte de la cuenca y de los corredores abiertos demuestra el desmantelamiento del sistema que se basaba en el pastoreo trashumante, que la cartografía documenta hasta la mitad del Ochocientos.

$\mathrm{El}$ avance del bosque sobre áreas que antes eran abiertas puede ser la primera muestra de los fenómenos de abandono que serán evidentes en los mapas siguientes. Las terrazas (413 ha) crecen en las laderas sobre Riomaggiore y Biassa. A su vez, en la zona sureste del área analizada se observa una contracción de las terrazas, substituidas por áreas boscosas (¿una primera muestra del abandono de las terrazas?). 


\section{CTR 1988}

El análisis del CTR 1988 (Fig. 5d) muestra la evolución de las dinámicas de abandono que se entrevieron en 1938. Las zonas al norte de la línea de cuenca son casi completamente boscosas. Allí se reconocen las neoformaciones de bosque (125 ha en 340 ha de zonas de bosque) que han determinado el cierre de una pequeña área abierta en el noreste del área de análisis y la contracción de lo que quedaba del área abierta en torno a la línea de cuenca, sobre todo en el sureste. Los pasillos abiertos en las terrazas ya no se observan, con la excepción de dos pequeñas trazas al sur del C. Lemmen y cerca del límite sureste del área de análisis. Los espacios abiertos en 1988 corresponden a poco más de 205 ha (90 ha menos que en 1938). Pero de estas la mayor parte corresponden a terrazas abandonadas. De hecho, en las laderas con terrazas, las áreas abandonadas (147 ha) aparecen mayoritariamente representadas como áreas abiertas (139 ha).

\section{CTR 1999}

El análisis del CTR 1999 (Fig. 5e) muestra la rápida evolución de las dinámicas de abandono: las áreas abandonadas corresponden a 440 ha (38\% del área analizada, Tabla 5), especialmente constituidos por neoformaciones de bosque (372 ha).

Al norte del límite de la cuenca las nuevas formaciones de bosque son particularmente evidentes, habiendo determinado la casi completa desaparición del área abierta cerca de

Tabla 7

RIOMAGGIORE. DINÁMICAS DEL USO DEL SUELO/CUBIERTA VEGETAL (1988-1999)

\begin{tabular}{|l|c|c|}
\hline \multicolumn{1}{|c|}{ Clasificación } & $\mathbf{1 9 8 8}$ (ha) & $\mathbf{1 9 9 9}$ (ha) \\
\hline áreas abiertas & 206,59 & 74,89 \\
\hline áreas de bosque & 340,35 & 319,6 \\
\hline áreas de terrazas & 294,69 & 267,08 \\
\hline $\begin{array}{l}\text { áreas abandonadas (terrazas abandonadas y neoformaciones de } \\
\text { bosque) }\end{array}$ & 273 & 443,55 \\
\hline
\end{tabular}

Tabla 8

RIOMAGGIORE. DINÁMICAS POST-CULTIVO (NEOFORMACIONES DE BOSQUE Y TERRAZAS ABANDONADAS) RECONOCIBLES DESDE 1988

\begin{tabular}{|l|r|r|}
\hline \multicolumn{1}{|c|}{ Hectáreas } & $\mathbf{1 9 8 8}$ (ha) & $\mathbf{1 9 9 9}$ (ha) \\
\hline neoformaciones de bosque en áreas abiertas & 125,31 & 253,21 \\
\hline neoformaciones de bosque en terrazas abandonadas & 8,73 & 118,97 \\
\hline \multicolumn{1}{|c|}{ Total neoformaciones de bosque } & $\mathbf{1 3 4 , 0 4}$ & $\mathbf{3 7 2 , 1 8}$ \\
\hline terrazas abandonadas representadas como áreas abiertas & 138,95 & 71,38 \\
\hline Total áreas abandonadas & $\mathbf{2 7 3}$ & $\mathbf{4 4 3 , 5 5}$ \\
\hline Total área de análisis & 1163,31 & 1163,31 \\
\hline
\end{tabular}


Mte. Parodi (restringida a 8 ha) y de las que circundan la cuenca, que permanecen solo cerca de C. Lemmen. Similar situación se verifica en los pasillos abiertos entre las terrazas: de estos se reconoce bastante bien únicamente uno al sur de C. Lemmen.

Las laderas con terrazas están cada vez más abandonadas (190 ha de terrazas en abandono y 267 que aparecen activas), sobre todo las situadas al norte de la línea de cuenca.

\subsection{La filtración cartográfica y las transformaciones en los sistemas de gestión de los recursos naturales}

La filtración cartográfica ha ofrecido elementos para la reconstrucción de las transformaciones del paisaje rural en la área de análisis, permitiendo seguir las dinámicas del uso del suelo y de la cubierta vegetal en un periodo de 180 años (Fig. 5).

De esta manera se han cuantificado y cualificado las transformaciones en la extensión de las áreas abiertas, de las zonas de bosque y de las terrazas. Siendo posible individualizar áreas de continuidad (como bosques o áreas abiertas) y conectarlas a las transformaciones en el sistema local de gestión de los recursos ambientales, desde un sistema múltiple de gestión (1820-1853) - donde coexistían viticultura especializada y prácticas de trashumancia - hasta un sistema de monocultivo conectado solo con la viticultura especializada (1853-1938) y con el abandono de las actividades agrícolas (1938-1999).

No obstante este análisis necesita verificación de campo para individualizar los rasgos físicos de los sistemas y sus transformaciones en la vegetación actual - a través investigaciones de ecología histórica - y en las estructuras edificadas (edificios y terrazas) - a través investigaciones de arqueología rural.

\section{Continuidad y discontinuidad: bosques, prados y terrazas}

La cartografía derivada de la filtración permite individuar los núcleos de «bosque antiguo» (84 ha), de «antiguas praderías» y las trazas de los corredores herbáceos de cresta (34 ha), que se conservan con continuidad desde 1820 (Fig. 6, Tab. 9) ${ }^{20}$. Estos son potenciales sitios de interés histórico-ambiental que solo las investigaciones de campo pueden verificar.

En particular, son muy relevantes los fragmentos de los corredores herbáceos (al sur de C. Lemmen y cerca del límite sureste del área de análisis), que son nodos de viabilidad, y que, por el mantenimiento abierto del hábitat mantuvieron en su vegetación las trazas vivas del antiguo sistema de trashumancia y del paso funcional de hombres y animales hacia la especialización productiva del área (fertilización de los viñedos en terrazas) ${ }^{21}$.

20 Para una explicación de los terminos «bosques antiguos» y «antiguas praderías» véase Cevasco, 2007 y Guido et al., 1996.

21 Las observaciones de ecología histórica realizadas en 2003 en tres zonas (C. Lemmen, Cacinagora y Telegrafo, localizados en la Fig. 6) mostraron que allí, dentro de la maquia mediterránea, cohabitaban, en claros o cerca de afloramientos rocosos, especies de praderas secas y especies de espacios «domesticados», con la presencia de buenas especies para el forraje de los prados-pastos (AA.VV., 2003: 84-85). En el sitio de la C. Lemmen se hicieron dos análisis del polen contenido en el suelo (en 2003 y 2008). Los resultados mostraron que los pólenes conservados en el suelo han registrado los cambios e la cubierta vegetal, y en particular el cambio de una cubierta predominantemente herbácea hasta una cubierta arbórea y arbustiva (Molinari C., Nuovo profilo pollinico di Case Lemmen aree aperte, castagneti e pinete, en AA.VV. 2009, pp. 195-201). 


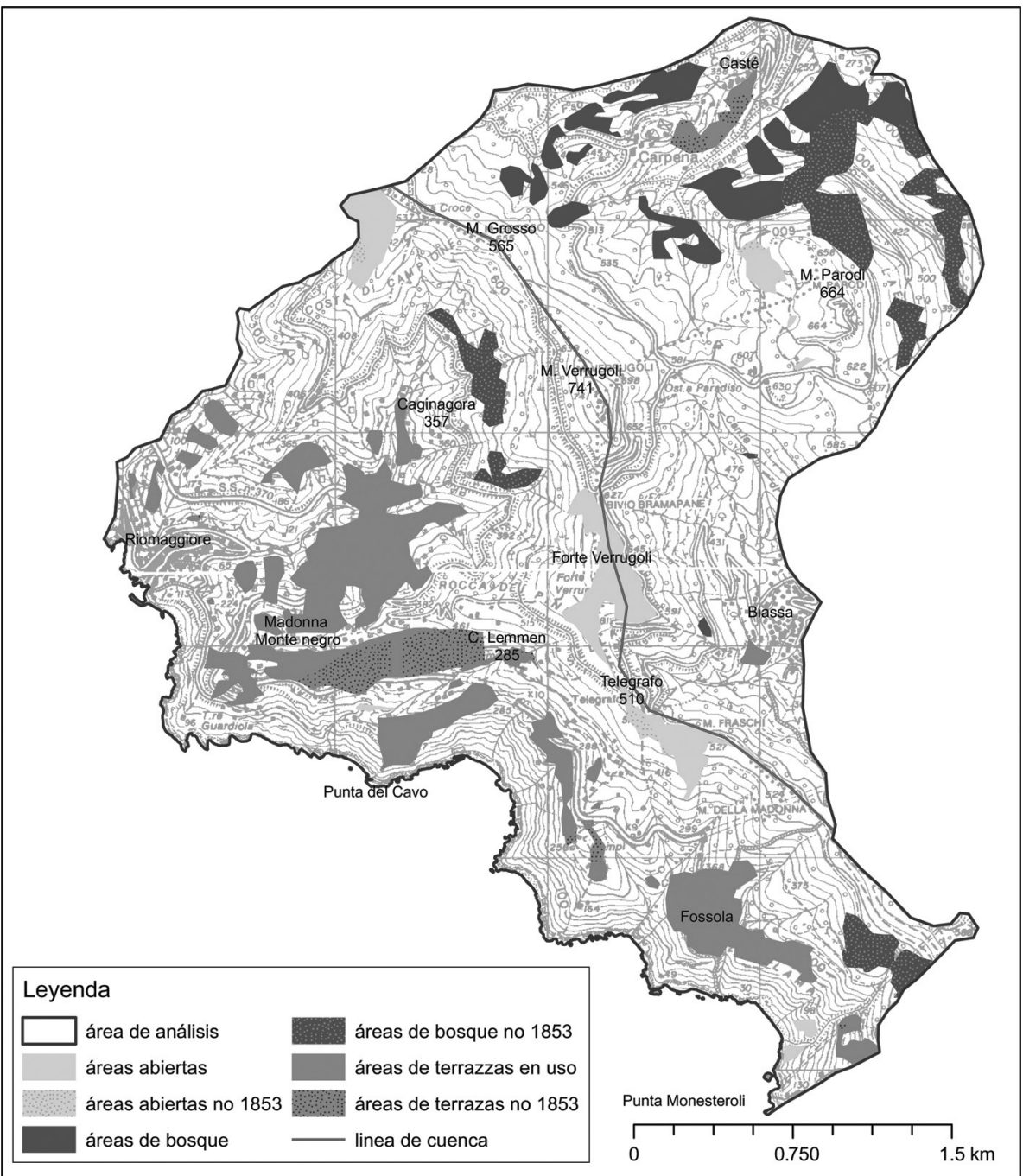

Figura 6. Riomaggiore, área de análisis. Continuidad del uso y cobertura vegetal (1820-1999).

Tabla 9

RIOMAGGIORE. DINÁMICAS DEL USO DEL SUELO/CUBIERTA VEGETAL (19881999). EXTENSION DE LAS AREAS DONDE FUE POSIBLE RECONOCER UNA CONTINUIDAD EN LA CUBIERTA VEGETAL DESDE 1820 HASTA 1999

\begin{tabular}{|l|c|l|c|}
\hline Continuidad 1820-1999 & Ha & Continuidad 1820-1999, con la exclusión del mapa 1853 & Ha \\
\hline áreas abiertas & 32 & áreas abiertas (con la exclusión de 1853) & 2,38 \\
\hline áreas boscosas & 38,12 & áreas boscosas (con la exclusión de 1853) & 45,5 \\
\hline áreas de terrazas & 92,94 & áreas de terrazas (con la exclusión de 1853) & 21,19 \\
\hline
\end{tabular}


Los análisis de campo permitirán también verificar qué superficie de las 114 ha de terrazas que aparecen en uso continuado desde 1820 hasta 1999, son hoy realmente utilizadas para el cultivo. La misma verificación debe ser realizada para las zonas de bosque antiguo. De hecho, este análisis no pretende verificar su uso real ${ }^{22}$.

\section{Antiguas praderías y corredores herbáceos}

En 1820, cuando las áreas abiertas eran un recurso activo como pastizal de invierno en las tierras colectivas y en los corredores herbáceos de las crestas, éstas ocupaban la parte más grande del área de análisis (el 45\%).

Con la filtración cartográfica, los pasillos herbáceos, que en 1820 serpenteaban en las laderas de terrazas, han sido reconocidos y analizados en su extensión y es posible reconstruir su progresivo encogimiento, acorde con la desaparición del sistema de trashumancia. Los corredores eran como «vías pecuarias» que se usaron como accesos a las tierras privadas de los viñedos en terrazas, cuando estos eran abiertos para el pasto de invierno. De esta manera, a través de la reconstrucción de la topografía de los corredores y de las áreas abiertas fue posible reconstruir la articulación del sistema que conectaba los pastos de la costa y los de la área de Zignago (en el Apenino) ${ }^{23}$.

Como se ve, las prácticas de trashumancia determinaron una estructura específica que caracterizaba las laderas de terrazas en función del pasto. Además, si en el cómputo de los recursos se calculan también las superficies de los viñedos, las áreas utilizadas por el pasto ocupaban el $75 \%$ del área de análisis.

Con el abandono del sistema de trashumancia, que era la estructura funcional que las utilizaba, las áreas y los corredores abiertos desaparecen progresivamente, y ya en 1938 no son reconocibles como parte de una estructura antes homogénea. En 1820 ocupaban casi 528 ha del área de análisis, en 1999 de éstas solo quedan 75 ha (Gráfico 1).

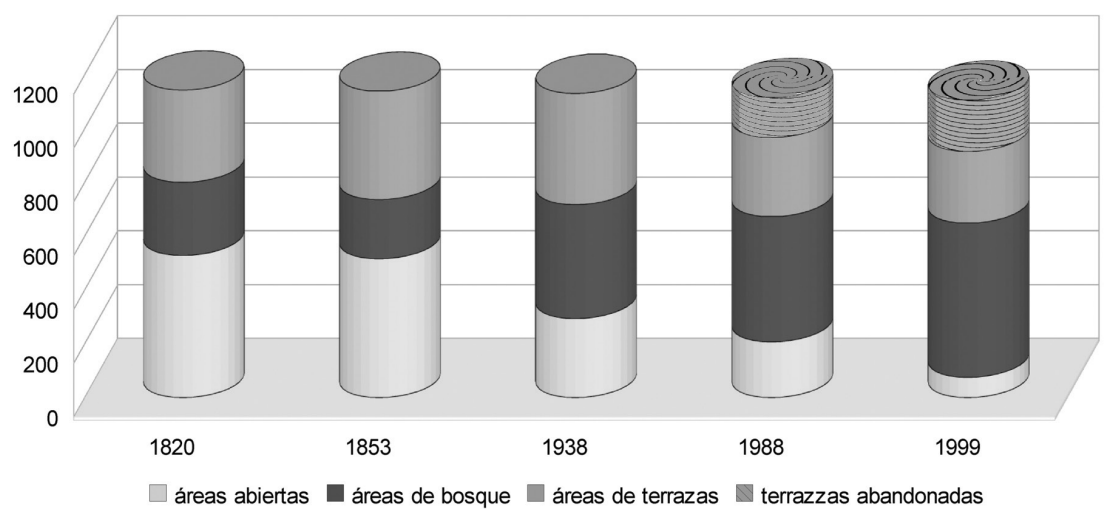

Gráfico 1. Riomaggiore. Dinámicas del uso y cobertura vegetal (1820-1999). Variaciones de las superficies (en ha) de áreas abiertas, de bosques y de terrazas.

22 Como se ha indicado en el epígrafe 2, esta investigación puede ser también realizada a través del estudio de las fotografías aéreas.

23 Este sistema busca comparaciones en otras áreas de la Liguria y del Mediterráneo (Palmero, Lassale, 2010). El análisis conducido sobre los mapas de la Gran Carta de 1853 relativos al área de las Cinque Terre y lo Zignago, permitió reconocer las rutas de la trashumancia entre la costa y el interior, gracias a la localización de las áreas representadas como «Gerbidi» (barbechos) o «Pascoli» (pastizales) (Stagno A. M., Individuazione dell'interesse storico dei paesaggi rurali nel Sito Unesco, en AA.VV., 2009 pp. 202-234). 


\section{FENÓMENOS DE ABANDONO Y EL PROBLEMA DE LA GESTIÓN DE LAS ÁREAS RURALES}

A través la filtración cartográfica ha sido posible evaluar la entidad de los fenómenos de abandono (Tabla 9, Gráfico 2), individualizar las direcciones de cierre de los prados y localizar las neoformaciones de bosque (Fig. 4). La dinámicas post-cultivo ligadas al abandono son evidentes desde 1988. En 1999, el 38\% del área de análisis está sujeta a fenómenos de abandono, reconocibles en las terrazas y en las áreas abiertas sustituidas por nuevas formaciones de bosque. El avance del bosque documentado en Riomaggiore es una parte del fenómeno generalizado de abandono de las áreas agrícolas y ganaderas que sufrió Europa occidental y el Norte de América, donde el aumento de las formaciones de bosque entre el año 1990 y el año 2000 ha sido estimado en 3,6 millones de hectáreas por año (Lambin et al., 2003, p. 209) ${ }^{24}$.

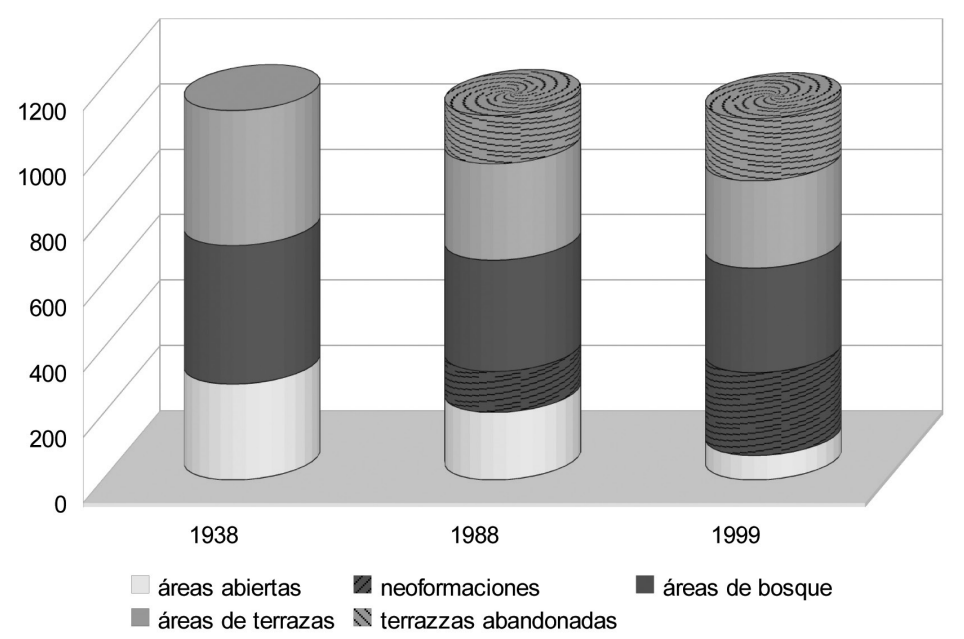

GráfICo 2. Riomaggiore. Dinámicas de post-cultivo (neoformaciones y terrazas abandonadas) reconocibles desde 1988 (en hectáreas).

Datos de este tipo pueden ser utilizados desde el punto de vista de la gestión del territorio. De hecho, los efectos del abandono de las actividades agrícolas son siempre objeto importante de investigación en el estudio de las áreas rurales de los países del Mediterráneo. Por ejemplo, a través del análisis de las fotografías aéreas (1972-1992), U. Rozin y A. P. Schick (1996) estudiaron los efectos del abandono de las actividades agrícolas y ganaderas sobre los procesos de erosión e hidrogeológicos en la región de Nahal Hoga (Israel). En la isla de Malta fueron estudiadas las dinámicas de abandono de los terrazas a través del análisis de imágenes de satélite y de fotografía aérea (Cyffka y Bock, 2008). En la región de Valencia, recientemente han sido estudiadas la dinámicas de abandono de las terrazas (Giménez Font, 2011).

Las investigaciones del LASA en el noroeste de Italia muestran que las áreas hoy sujetas a protección nacional e internacional por la presencia de hábitats prioritarios para la flora

24 Desde el comienzo del siglo XX, en todo el mundo el abandono ha afectado a 222 millones de hectáreas de tierras de cultivo, principalmente en Europa Occidental y América del Norte (Lambin, et al., 2003). 
y la fauna (LICS de la Red Natura 2000, Parques Naturales y otras figuras de protección regionales como ZPP y ZRC), estuvieron, hasta el final de siglo XIX, incorporados en sistemas múltiples de carácter agro-silvo-pastoriles conectados con la trashumancia. En estos sistemas, el pastoreo de ovejas y ganado vacuno jugó un papel clave en el diseño de los paisajes rurales y en el favorecimiento de la fertilización de los cultivos y el desarrollo de la biodiversidad animal y vegetal. Por ello, no es casual que el área de Riomaggiore también se inserte en una figura de protección (el Parque Natural Nacional de las Cinque Terre).

Actualmente, debido al creciente abandono de las actividades agrícolas, se plantea el problema de individualizar políticas de gestión que promuevan la conservación del patrimonio natural (e histórico) de las áreas rurales, formado a través de un proceso tan complejo. Está demostrado, de hecho, que la biodiversidad disminuye en proporción con el grado de abandono de las actividades agrícolas tradicionales.

Como se ha demostrado con el estudio de caso de Riomaggiore, la situación actual es un resultado de la suma de una serie de transformaciones, visibles únicamente retrocediendo en el tiempo casi dos siglos. De esta manera, es posible identificar las dinámicas históricas que determinaron la formación de los paisajes actuales (y caracterizar históricamente su ecología), manteniendo su complejidad. En los estudios sobre las transformaciones del uso del suelo y de la cubierta vegetal es notorio señalar cómo la reconstrucción de esta complejidad debe ser el primer paso para la elaboración de políticas de gestión de las áreas rurales que, considerando las características y los procesos específicos de cada una de ellas, individualicen medidas eficaces para el mantenimiento de la biodiversidad y también de las características de los paisajes rurales ${ }^{25}$.

\section{Referencias bibliográficas}

AA.VV. (2009): Individuazione di siti di interesse storico-archeologico ambientale nel Sito UNESCO «Cinque Terre, Portovenere e le Isole» con i metodi dell'archeologia rurale e dell'ecologia storica, Relazione finale ed elaborati, DipTeRis, DiSMeC, LASA, Università degli Studi di Genova, 388 pp.

AA.VV. (2010): Les paysages de l'arbre hors forêt : multi-valorisation dans le cadre d'un développement local durable dans les moyennes montagnes du Sud de l'Europe, relation final du Projet., DipTeRis, DiSMeC, LASA, Università degli Studi di Genova, 100 pp. AA.VV. (2003): Siti Lemmen e Cacinagora (Riomaggiore, SP). Studi e ricerche finalizzati all'identificazione delle dinamiche storiche dell'area, effetti delle pratiche agro-silvopastorali e dinamiche post-colturali della copertura vegetale. Relación de investigación, DipTeRis, DiSMeC, LASA, Università degli Studi di Genova, 350 pp.

AGRAWAL, A. (2003): «Sustainable governance of common-pool resources: context, methods, and politics», Annu. Rev. Anthropol. 2003 (32), pp. 243-62.

AGRAWKL, A., GIBSON, C. C., coord. (2001): Communities and Environment, Rutger University Press, $205 \mathrm{pp}$.

ANDERSON, J. R., HARDY, E. E., ROACH, J. T., WITMER, R. E. (2001): «A Land Use And Land Cover Classification System For Use With Remote Sensor Data», en Geological Survey Professional, nº 964 (revisión del original publicado en el 1976).

25 En este ámbito, son muy numerosas las propuestas de gestión que señalan en la valorización de la gestión local la llave para la conservación del medio ambiente (Agrawkl y Gibson, 2001). La propuesta consiste en retornar a los productores agrícolas locales un papel clave en el plano de la gestión, porque está demostrado como las actividades tradicionales de las economías agro-silvo-pastoriles fueron y son determinantes en el mantenimiento y en la activación de los paisajes y recursos ambientales (Krzywinski et al., 2007; Moreno y Montanari, 2008). 
CEVASCO, R. (2007): Memoria verde. Nuovi spazi per la geografia, Ed. Diabasis, Reggio Emilia, 300 pp..

CEVASCO, R., MARULLO, E., STAGNO, A. M. (2005): «L'analisi della cartografia storica per lo studio delle variazioni della copertura vegetale nel SIC RoccaGrande-M.te $\mathrm{Pu}$ (Liguria orientale)», en Actas de la 9a Conferenza Nazionale ASITA (Federazione delle Associazioni Scientifiche per le Informazioni Territoriali e Ambientali)», Catania, pp. 683-688.

CINGOLANI, A. M., ZAKA, M. R., CABIDOA, M. R. (2004): «Mapping vegetation in a heterogeneous mountain rangeland using landsat data: an alternative method to define and classify land-cover units», en Remote Sensing of Environment, Vol. 92 (1), pp. 84-97.

CLARK, J., DARLINGTON, J., FAIRCLOUGH, G. (2004): Using Historic Landscape Characterisation, English Heritage, North Yorkshire, 63 p.

CLARKE, K C, HOPPEN, S., GAYDOS, L. (1997): «A self-modifying cellular automaton model of historical urbanization in the San Francisco Bay area», en Environment and Planning B: Planning \& Design 24 (2), pp. 247- 260.

COLWELL, R. N. (1983): Manual of Remote Sensing (vol. 1 \& 2), American Society of Photogrammetry, Falls Church, Virginia, USA.

CYFFKA, B., BOCK, M. (2008): «Degradation of field terraces in the Maltese Islands. Reasons, processes and effects», en Geogr. Fis. Dinam. Quat., 31, pp. 119-128.

FULLER, R.M., GROOM, G.B., JONES, A.R. (1994): «Land cover map of Great Britain. An automated classification of Landsat Thematic Mapper data», en Photogrammetric Engineering and Remote Sensing Journal, Vol. 60 (5), pp. 553-562.

GASPARINI, G.P. (2001): «Il «Libro dei conti» di una bottega di carne della prima metà dell' Ottocento: un quadro dell' economia quotidiana di una comunità agricola della Liguria Orientale», en Rivista di Storia dell'A Aricoltura, XLI(1), pp. 3-71.

GIMÉNEZ FONT, P. (2011): «The landscape of agricultural terraces in mountainous areas in the Region of Valencia (Eastern Spain). The construction and decline of a cultural heritage», en Agricultural and Tourism. Products and Local Development. Rabat: International Union Geography.

GOLDEWIJK, K., RAMANKUTTY, N. (2004): «Land cover change over the last three centuries due to human activities: The availability of new global data sets», en Geojournal, $\mathrm{n}^{\circ}$ 61, pp. 335-344.

GOWARD, S., WILLIAM, D. (1997): «Landsat and earth system science: Development of terrestrial monitoring», en Photogrammetrci Engineering and Remote Sensing, $\mathrm{n}^{\circ}$ 63, pp. 887-900.

GUIDO, M.A., MORENO, D., MONTANARI, C., POGGI, G. (1996): «Antiche praterie e rimboschimenti del XIX secolo: studi di storia della copertura vegetale», en Giorn. Bot. Ital., 130(1), pp. 320-327.

GURRUTXAGA SAN VICENTE, M., LOZANO VALENCIA, P. J. (2007): «Criterios para contemplar la conectividad del paisaje en la planificación territorial y sectorial, Investigaciones Geográficas, $\mathrm{n}^{\circ}$ 44, pp. 75-88

KRZYWINSKI K., OCONNELL M., KUSTER H. (coord.), Cultural Landscapes of Europe, Fields of Demeter, Haunts of Pan, WILDESHAUSEN: Aschenbeck \& Oeljeschläger (Germany), $150 \mathrm{p}$.

LAMBIN, E. F., GEIST, H., RINDFUSS, R. R. (2006): «Introduction: Local processes with global impacts», en Lambin, E., Geist, H.J. (eds.), Land-Use and Land-Cover Change. Local Processes and Global Impacts, Springer Verlag, Berlin, pp. 1-8.

LAMBIN E. F., GEIST, H., LEPERS, E. (2003): «Dynamics of land-use and land-cover change in Tropical Regions», en Annu. Rev. Environ. Resour., n 28, pp. 205-241. 
LOVELAND, T. R., SOHL, T., SAYLER, K., GALLANT, A., DWYER, J., VOGELMANN, J., ZYLSTRA, G., WADE, T., EDMONDS, C., CHALOUD, D., JONES, B. (1999): Land Cover Trends: Rates, Causes, and Consequences ofLate-Twentieth Century U.S. Land Cover Change Research Plan, EPA-IAG Project n. DW14938108-01-0, EPA/600/R-99/105 June 1999, p. 1-52.

MAGGI, R., DE PASCALE, A., GUIDO, M.A., MANNONI, T., MONTANARI, C., MORENO, D., (2006): «Per un'archeologia delle Cinque Terre», en Musso S.F., Franco G. (coord.),Guida agli interventi di recupero dell'edilizia diffusa nel Parco Nazionale delle Cinque Terre, Marsilio ed., Venezia, pp.45-60.

MAGGI, R., MONTANARI, C., MORENO, D. (coord.) (2002): «Atti del Seminario Internazionale «L'approccio storico-ambientale al patrimonio rurale delle aree protette», Torriglia e Montebruno (GE)», en Archeologia Postmedievale 6, 2002, pp. 9-214.

MONTANARI, C., GUIDO, M.A., MORENO, D. (2010): «Archeologia e storia delle risorse ambientali in Liguria: attività di terreno del L.A.S.A. (1996-2004)», en Odetti G. (coord.), L'uomo e la terra ligure (Genova 10-11 febbraio 2005), Genova, pp. 101-114

MORENO, D. (1990): Dal documento al terreno. Storia e archeologia dei sistemi agrosilvo-pastorali, Il Mulino-Ricerche, Bologna 1990, 276 pp.

MORENO, D. (1995): «Une source pour l'histoire et l'archeologie des ressources végétales. Les cartes topographiques de la montagne ligure (Italie)», en Bosquet-Bressolier C. (coord.), L'oeil du cartographe et la représentation géographique du Moyen Age à nos jours, Paris, CTHS, 175-198.

MORENO, D., MONTANARI, C. (2008): «Màs allà de la percepción: hacia una ecología histórica del paisaje rural en Italia», en Cuadernos Geográficos de la Universidad de Granada, vol. 43; p. 29-49.

MORENO, D., MONTANARI, C., STAGNO, A.M., MOLINARI, C. (2010): «A plea for a (New) Environmental Archaeology: the use of the geographical historical microanalitical approach in mountain areas of NW Italy», en Tzortzis S. et Delestre X. (eds.), Archéologie de la montagne européenne, Actes de la table ronde internationale, Gap, 29 septembre-1er octobre 2008, Bibliothèque d'archéologie méditerranéenne et africaine 4, Paris : Errance, pp. 75-83.

MORENO, D., POGGI, G. (1996): «Storia delle risorse boschive nelle montagne mediterranee: modelli di intepretazione per le risorse foraggere in regime consuetudinario», en L'uomo e la foresta sec. XIII-XVIII, Atti della XXVII Settimana di Studi - Istituto "F. Datini” Prato, Le Monnier, Firenze, pp. 635-653.

MORENO, D., RAGGIO, O. (1990): «The making and fall of an intensive pastoral landuse-system. Eastern Liguria, 16-19 ${ }^{\text {th }}$ c.», en Maggi R., Nisbet R., Barker R. (coord.), Archeologia della pastorizia nell'Europa meridionale, en Rivista di Studi Liguri, A. LVI.(1-4), pp. 193-217.

MULKOVA, M., POPELKOVÁ, R. (2010): «The aerial photos to detect changes in the landscape affected by black coal deep mining», en Wagner W., Székely, B. (eds.), ISPRS TC VII Symposium - 100 Years ISPRS, Vienna, Austria, IAPRS, Vol. XXXVIII, Part 7B, pp. 401-406.

NAGENDRA, H., MUNROE, D. K., SOUTHWORTH, J. (2004): «From pattern to process: Landscape fragmentation and the analysis of land use/land cover change», en Agric., Ecosyst. Environ., $\mathrm{n}^{\circ} 101, \mathrm{pp} .111-115$.

PEÑA, Ó., OSTERTAG, G., GANDULLO, R., CAMPO, A. (2008): «Comportamiento de la vegetación de un humedal (mallín) entre períodos húmedos y secos mediante análisis hidrológico y espectral», en Investigaciones Geográficas, n. ${ }^{\circ}$ 45, pp. 229-249. 
PAEGELOW, M., CAMACHO OLMEDO, M. T. (2003): «Le processus d'abandon des cultures et la dynamique de la reconquête végétale en milieu montagnard méditerrnanéen: L'exemple des Garrotxes (P.O. France) et de la Alta Alpujarra Granadina (Sierra Nevada, Espagne)», en Sud Ouest Européen, n 16, pp. 113-130.

PALMERO, B., LASSALE, J., (2009): «L'exploitation pastorale des territoires de confins de la haute vallée de la Roya à travers les sources écrites (XIIe-XVIIe siècle). Contribution à une approche pluridisciplinaire», en Tzortzis S., Delestre X. (coord.), Actes des la table ronde: archéologie de l'espace montagnard: confrontation d'expériences européennes, GAP, pp. 85-95.

PETIT, C. C., LAMBIN, E. F. (2002): «Impact of data integration technique on historical land-use/land-cover change: Comparing historical mapes with remote sensing data in the Belgian Ardennes», en Landscape Ecology (2002), vol. 17 (2), Publisher: Springer, pp. 117-132.

PU, R., GONG, P. (1998): «Predicting Land-Cover Changes with Gray Systems Theory and Multitemporal Aerial Photographs», en Annals of GIS, vol. 4 (1-2), pp. 73-79.

RAGGIO, O. (1992): «Forme e pratiche di appropriazione delle risorse. Casi di usurpazione delle comunaglie in Liguria», en Quaderni Storici, $\mathrm{n}^{\circ}$ 79, pp. 135-168.

RAMANKUTTY, N. (2006): «Global Land-Cover Change: Recent Progress, Remaining Challenges», en Lambin E. F., Geist H. (eds.), Land-Use and Land-Cover Change. Local Processes and Global Impacts, Springer-Verlag Berlin Heidelberg, pp. 9-40.

RAMANKUTTY, N, FOLEY, J., OLEJNICZAK, N. J. (2002): «People on the land: changes in global population and croplands during the 20th century», en Ambio 31(3), pp. 251-57.

RECATALÁ BOIX L., AÑÓ VIDAL C., VALERA LOZANO A., SÁNCHEZ DÍAZ J. (2009): «Sistema de indicadores para evaluar la calidad ambiental y la desertificación en la Comunidad Valenciana», en Investigaciones Geográficas, no 50 (2009) pp. 5-18.

RENDU, C. (2003), La montagne d'Enveig, un estive pyréneénne dans la longue durée, éd. du Trabucaire, Perpignan, 600 pp.

RODGERS, C. P., STRAUGHTON, E. A., WINCHESTER A. J. L., PIERACCINI M., (2010): Contested Common Land: Environmental Governance Past and Present, London: Earthscan, 240 p.

RICHARDS, J. A., JIA X. (2006): Remote sensing digital image analysis: an introduction (four edition), Berlin-Heidelberg, $441 \mathrm{pp}$.

ROZIN, U., SCHICK, A. P. (1996): «Land use change, conservation measures and stream channel response in the Mediterranean/semiarid transition zone: Nahal Hoga, Southern Coastal Plain, Israel», en Erosion and Sediment Yield: Global and Regional Perspectives (Proceedings of the Exeter Symposium, IAHS Publ., $\mathrm{n}^{\circ} 236$, pp. 427-444.

SEDDA, L., DELOGU, G., DETTORI, S. (2011): «Forty-Four Years of Land Use Changes in a Sardinian Cork Oak Agro-Silvopastoral System: A Qualitative Analysis», en The Open Forest Science Journal, 4, pp. 57-66.

SHABAN, M.A., DIKSHIT, O. (2001): «Improvement of Classification in Urban areas by the Use of Textural Features the Case Study of Lucknow City, Uttar Pradesh», en International Journal of Remote Sensing, 22(4), pp. 565-593.

STAGNO, A. M., 2009, «Geografia degli insediamenti e risorse ambientali: un percorso tra fonti archeologiche e documentarie (Ventarola, Val d'Aveto, Rezzoaglio GE)», en Macchi Janica G. (coord.), Geografie del Popolamento. Casi di studio, metodi e teorie. Convegno di studi Grosseto 24-26 settembre 2008), pp. 301-310 (http://www. archeogr. unisi.it/testi/).

STAGNO, A. M., TIGRINO, V. (2011 en prensa): «Risorse locali, conflitti e istituzioni. Il rapporto tra beni comuni, proprietà particolari e intervento «pubblico» (Appennino 
Ligure, XVIII-XX s.)», en Nervi P. (coord.), Atti della XVI riunione scientifica del Centro studi e documentazione sui demani civici e le proprietà collettive. Le terre di collettivo godimento tra bene comune e proprietà Trento, 25-26 novembre 2010, en Archivio Scialoja - Bolla.

STORTI, M. (2007): I luoghi detti del paesaggio rurale. Riomaggiore, Manarola, Groppo e Volastra, Edizioni del Parco delle Cinque Terre, La Spezia, 157 pp.

THONGMANIVONG, S., FUJITA, Y., PHANVILAY, K., VONGVISOUK, T. (2011): "Agrarian Land-Use Transformation in Northern Laos: from Swidden to Rubber», en Southeast Asian Studies, vol. 47 (3), pp. 330-347 (http://kyoto-seas.org/2011/02/ southeast-asian-studies-vol-47-no-3).

WILSON, E. H. et. al. (2003): «Development of a geospatial model to quantify, describe and map urban growth», en Remote sensing of environment, 86, pp. 275-285.

WOODS, C. H., SKOLE, D. (1998): «Linking satellite, census, and survey data to study deforestation in the Brazilian Amazon», en Liberman D. et al. (coord.) People and Pixels: Linking Remote Sensing and Social Science, National Academy Press, Washington, DC, USA, pp. 70-90.

ZENG, X., DICKINSON, R. E., WALKER, A., SHAIKH, M. (1999): «Derivation and Evaluation of Global 1-km Fractional Vegetation Cover Data for Land Modeling», en Journal of Applied Meteorology, Vol. 39, pp. 826-839.

ZHANG, Z., PETERSON, J., ZHU, X., WRIGHT, W. (2007): «Modelling land use and land cover change in the Strzelecki Ranges», en MODSIM07 International Congress on Modelling and Simulation, Christchurch, New Zealand., pp. 1328-1334 (http://eprints. usq.edu.au/4033/). 
